\title{
Avaliação informacional em ambientes colaborativos
}

\author{
Jaires Oliveira $S$ antos \\ Doutoranda; Universidade Federal da Bahia, Salvador, BA, Brasil; \\ jaires.oliveira@ufba.br \\ Maria Isabel de Jesus Sousa Barreira \\ Doutora; Universidade Federal da Bahia, Salvador, BA, Brasil; \\ isasousa@ufba.br \\ Larissa de LimaSouza \\ Graduanda; Universidade Federal da Bahia, Salvador, BA, Brasil; \\ laah.limasouza@gmail.com \\ Michelle Pacheco Gomez \\ Graduanda; Universidade Federal da Bahia, Salvador, BA, Brasil; \\ michelle.p.gomez@hotmail.com
}

\begin{abstract}
Resumo: Esta pesquisa ${ }^{1}$ visa analisar de que maneira os bibliotecários economicamente ativos avaliam a informação em ambientes colaborativos. Para alcançar esse objetivo, delineou-se o percurso metodológico. Trata-se de uma pesquisa descritiva, combinando as abordagens qualitativa e quantitativa. $\mathrm{O}$ universo foi constituído dos bibliotecários em atividade, com registro ativo até março de 2019 no Conselho Regional de Biblioteconomia da quinta região (CRB5), que à época contabilizava 595 profissionais. Contudo, apenas os 116 bibliotecários que responderam ao instrumento de coleta de dados puderam ser contemplados na amostra. Os resultados demonstraram que há cenários favoráveis em relação à avaliação da informação na atividade laboral do bibliotecário, entretanto, foi possível perceber fragilidades consideradas um tanto preocupantes, dentre as quais a de alguns profissionais não conseguirem distinguir informações de desinformações.
\end{abstract}

Palavras-chave: Avaliação da informação. Tecnologias de informação e comunicação. Ambientes colaborativos. Competência em informação. Desinformação.

\section{Introdução}

A avaliação da informação inclui diversos fatores. Em ambientes cada vez mais colaborativos, parece ser uma realidade a necessidade de atentar, dentre esses fatores, à precisão, atualização, confiabilidade, suficiência, relevância, origem e concisão/objetividade da informação, para que os sujeitos não sejam iludidos 


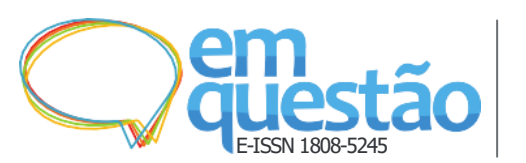

por desinformação. Quando se trata dos bibliotecários ativos no mercado de trabalho, isso se torna mais evidente, tendo em vista que ao trabalhar a competência em informação desses profissionais em projetos de pesquisa, questões relacionadas à avaliação aparecem como grandes potenciais a serem investigados.

A ideia da plataforma colaborativa pressupõe um lugar de aprendizagem, onde se resolvem problemas de forma participativa e se aplicam competências especificas requeridas pelo contexto no qual as pessoas estão inseridas. A característica da interação tem primordial relevância na conjuntura atual da Biblioteconomia, que tem explorado as potencialidades da internet e das mídias digitais para (re)configurar a sua própria práxis. Ademais, entende-se que as competências individuais, combinadas com as de outras pessoas, contribuem para que o trabalho seja efetivamente de qualidade e aplicável no contexto social em voga.

Nessa dimensão, Amaro (2018) afirma que o aumento do número de usuários das redes socais, bem como o uso de ambientes informacionais na web, é uma realidade universal; contudo, é preciso encarar esses espaços como ambientes educativos e de interação entre diferentes pessoas e localidades, nos quais a tecnologia representa um poderoso instrumento de aprendizado e de comunicação.

Sabe-se, logo, que as tecnologias da informação e comunicação (TIC) se tornaram aliadas de tantas profissões, mas admite-se que é necessário um processo educativo para o seu uso efetivo. Desse modo, é inevitável perceber que o bibliotecário precisa desenvolver um aprendizado crítico/reflexivo acerca do uso de informações em ambientes interativos. Diante dessas questões, surge o objetivo deste artigo: analisar de que maneira os bibliotecários, economicamente ativos, avaliam a informação em ambientes cada vez mais colaborativos.

Para responder a esta pretensão, traçou-se o percurso metodológico. Trata-se de uma pesquisa descritiva, combinando a abordagem qualitativa e quantitativa. Investigaram-se os bibliotecários ativos no mercado de trabalho; para contatá-los, contou-se com o apoio do Conselho Regional de Biblioteconomia da quinta região (CRB5), que forneceu dados relativos ao 


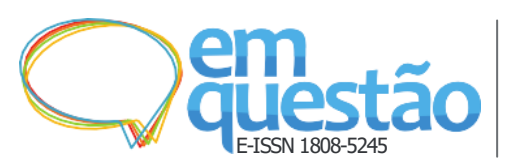

quantitativo de profissionais com cadastro ativo e enviou o instrumento de coleta de dados aos respondentes. O universo da pesquisa foi de 595 bibliotecários ativos no estado da Bahia, ao passo que a amostra foi constituída de 116 profissionais que responderam à pesquisa.

\section{A avaliação informacional}

A Ciência da Informação (CI) caminha no sentido de um horizonte interdisciplinar, agregando, logo, várias outras ciências no decurso do fortalecimento de seu objeto de estudo. Saracevic (1996) reforça a colaboração que a CI tem oferecido para as problemáticas informacionais da sociedade ao longo dos anos. Dentre outras questões, aqui se mencionam aquelas relativas às competências profissionais, que inevitavelmente incluem um processo de avaliação informacional.

Nesse sentido, é perceptível o quanto a ascensão das TIC trouxe ressignificações para o tratamento dos conceitos da área em questão. Assim, Hatschbach e Olinto (2008) ratificam que as demandas da sociedade da informação fizeram emergir novas bases conceituais, estruturas físicas e virtuais, além de tecnologias para o aprendizado e a aquisição de conhecimento, evidenciando, portanto, a competência em informação como uma questão indispensável.

Belluzo (2018) trata a competência em informação como um reconhecimento social da capacidade de um indivíduo de emitir opinião a respeito de algo. Posteriormente, esse conceito passou a ser utilizado para qualificar o indivíduo capaz de realizar determinado trabalho e administrar conhecimentos, em diversos ambientes socioculturais. Nesse sentido, concordase que esse conceito tem estreita relação com a teoria freiriana (FREIRE, 1987), que propõe a ideia de que o sujeito não deve ser ensinado a repetir palavras, mas sim pensá-las, criticamente, para que quando necessário seja capaz de saber e dizer a seu modo. Outrossim, Carneiro e colaboradores (2018) acenam para a evidência de que a competência em informação, além de representar questões ligadas ao fazer do bibliotecário, assumiu, de modo incremental e evolutivo, contornos que viabilizam o aprendizado ao longo da vida. 
Nessa direção, é necessário que se tome nota da avaliação da informação. Sem essa condição, o sujeito enfrenta dificuldades para identificar situações de desinformação. Os debates sobre esse conceito acirraram-se em circunstâncias essencialmente políticas, como no referendo do Reino Unido e principalmente nas eleições dos Estados Unidos, em 2016 (VALENZUELA et al., 2019). As eleições presidenciais do Brasil, em 2018, também foram conduzidas em meio à repercussão de tais fenômenos.

Concorda-se nesse estudo que a desinformação compreende as notícias com conteúdo falso, errado, enganoso, ilusório e/ou satírico. O comportamento dos sujeitos em relação às desinformações tem sido uma temática muito investigada na atualidade. Isso porque envolve implicações ao assimilá- las como verdadeiras e/ou com a clareza de que se trata de desinformações e, ainda assim, resolve compartilhar e considerar como pertinente, pois vão ao encontro de seus valores e coadunam com a sua visão política e social. Ruokolainen e Widén (2020) afirmam que as narrativas ajudam a compor a complexidade desse cenário, uma vez que, em meio a abundantes informações produzidas e disseminadas, imperam também as desinformações. As pessoas costumam sentir-se seduzidas em atribuir credibilidade às notícias com narrativas dominantes naquele contexto social.

Evidentemente que em ambientes informacionais web, essa preocupação se mostra ainda mais patente. Lemos e Lévy (2010) anunciavam que a Internet é, de fato, um vetor de liberação da palavra, referindo-se à ideia de que uma democratização de acesso permitia aos sujeitos que se expressassem nesses lugares, nos quais conversam por meio de chat, colaboram por meio de comentários, compartilham e publicam conteúdos em redes sociais e, ademais, visitam uma infinidade de sítios, blogs, ouvem podcasts e interagem com podcasts, independentemente do lugar do mundo onde estejam fisicamente. Valenzuela e colaboradores (2019) ponderam acerca da existência de tantos pontos positivos dessa possibilidade de participação (política) democrática dos sujeitos em seu uso das mídias sociais, contudo afirmam que existe uma corrente de estudiosos que apontam essa dinâmica como negativa, em vista da propagação de desinformações nesses ambientes. 


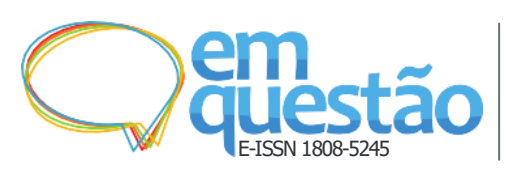

Ao pensarmos nos desafios que permeiam o transcurso avaliativo da eleição informacional, torna-se mister recuperar a perspectiva de Schwab (2016), que apresenta os estágios de evolução da sociedade. Ele diz que, entre o meio do século XVIII e o meio do século XIX, vivenciou-se a Primeira Revolução Industrial, durante a qual se utilizou a água e o vapor para mecanizar a produção. Em seguida, veio a Segunda Revolução Industrial, que usou a eletricidade para criar a produção em massa. Durante a Terceira Revolução Industrial, as TIC e os dispositivos eletrônicos se mostraram evidentes, especialmente no que tange aos processos de automatização da produção na segunda metade do século XX. Mais recentemente, o autor ainda faz alusão a uma quarta revolução, que seria aquela da convergência, isto é, a era em que a conectividade faz parte do cotidiano dos sujeitos e em que, portanto, estes tendem a adequar-se a essa realidade premente.

Ao discutir o fazer bibliotecário, estudos de Santos (2015) e de Santos e Barreira (2019) já apontavam a necessidade de o profissional da informação, seja ele bibliotecário ou arquivista, atentar para a realidade desse período de convergência. Esses autores destacavam, sobretudo, a relevância do desenvolvimento e emprego de competência em informação, que certamente

[...] é fundamental para que consigam ter atitudes proativas em suas tarefas diárias, seja para promover a disseminação da informação, elaborar projetos, criar novos produtos informacionais, seja para adaptar os recursos já disponíveis na biblioteca, incluindo o uso das redes sociais. Assim, buscará melhor atender as demandas informacionais dos cidadãos e ser um elemento de aproximação da instituição à nova geração de usuários, bem como criar um espaço para realizar o marketing institucional, a difusão dos acervos e eventos culturais. (SANTOS; BARREIRA, 2019, p. 5).

Tem-se, então, essa realidade da quarta revolução, caracterizada pela fusão de tecnologias que estão fazendo desaparecer as linhas entre a esfera física, a esfera digital e a esfera biológica. A esfera física consiste no aspecto tangível. A esfera digital refere-se ao elo entre os sujeitos e o meio digital. $\mathrm{Na}$ chamada internet das coisas, plataformas e dispositivos, conectados entre si, passam a intermediar a interação entre as pessoas e as coisas e a ligar meio digital a meio físico. Por fim, a esfera biológica reflete as transformações no 


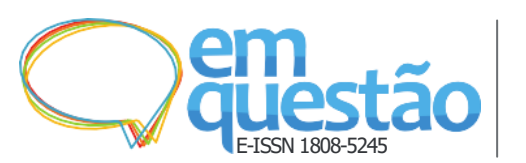

campo da biologia sintética, que têm permitido criar organismos modificados geneticamente, gerando dilemas éticos, morais e jurídicos (SCHWAB, 2016).

Nesse cenário de mudanças constantes, o profissional da informação desenvolve habilidades cada vez mais específicas para saber lidar com as demandas que naturalmente exigem o manuseio de recursos tecnológicos em seu ambiente laboral. De acordo com Queiroz (2014), a competência é um conjunto de conhecimentos que permite desenvolver bem uma tarefa. Para adquirir uma competência, é necessário todo um processo cognitivo que perpassa as questões do processo de aprendizagem e é preciso, evidentemente, uma constante avaliação.

O estudo produzido pela Comissão das Comunidades Europeias (2000) intitulado Memorando sobre aprendizagem ao longo da vida apresenta três categorias de aprendizagem, sendo elas: formal, não formal e informal. A aprendizagem formal se dá nas instituições de ensino e formação e conduz a diplomas e qualificações. A não formal, por sua vez, decorre em paralelo aos sistemas de ensino e formação, mas não necessariamente oferece certificações formais. Pode ocorrer no local de trabalho, através de atividades de organizações ou grupos da sociedade civil (organizações de juventude, sindicatos e partidos políticos). Por fim, existe a aprendizagem informal, que é um acompanhamento natural da vida cotidiana, um tipo de aprendizagem não intencional, e que pode não ser reconhecida, mesmo pelos próprios indivíduos, como enriquecimento dos seus conhecimentos e aptidões.

O documento aborda o fato de que, até o momento, a aprendizagem formal tem dominado o pensamento político, moldando a forma como a educação e a formação são ministradas, influenciando as percepções dos indivíduos sobre o que é ou não importante em termos deaprendizagem. Discute ainda que a aprendizagem informal não é priorizada, ainda que seja a forma mais antiga de aquisição de conhecimento, trazendo, por exemplo, a ideia de que a tecnologia foi implantada nos domicílios antes mesmo de se estabelecer nas instituições, sublinhando, logo, a importância da aprendizagem informal.

O processo de aprendizagem congrega o conceito de metacognição, que, na visão de Ribeiro (2003), refere-se ao conhecimento do próprio conhecimento, 


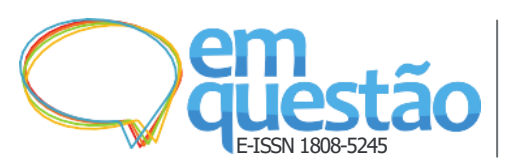

à avaliação, à regulação e à organização dos próprios processos cognitivos. Nesta dinâmica, é inevitável ratificar o quanto que o processo avaliativo é algo salutar, tendo em vista que conduzirá ao acesso a informações assertivas, para sanar necessidades no contexto de aprendizagem, para aplicação na vida pessoal ou laboral. Ao aprofundar a discussão, a autora salienta que a metacognição é composta por três variáveis: pessoa, tarefa e estratégia.

A variável pessoa comporta três categorias de conhecimento: intraindividual (conhecimento sobre si próprio, áreas fortes e fracas, interesses, atitudes etc.), interindividual (conhecimento sobre as diferenças entre si próprio e os outros) e universal (todo conhecimento dominante numa cultura que veicula certas ideias acerca da aprendizagem). A variável tarefa se refere à natureza da informação com que um sujeito é confrontado (escassa ou abundante, imprecisa ou rigorosa) e aos critérios da tarefa a realizar. Aqui, a informação ou o material a aprender variam, em função da sua familiaridade e da forma como são apresentados, devendo o sujeito adaptar as suas respostas a essas características. Ou seja, diferentes tipos de tarefas exigem diferentes tipos de processamento de informação. Por fim, existe a variável estratégia, que inclui informações sobre os meios, processos ou ações que permitem ao sujeito atingir os objetivos com maior eficácia numa determinada tarefa. Agora, possuir um repertório razoável de estratégias já não é mais o suficiente, é necessário também ter um conhecimento aprofundado sobre elas (RIBEIRO, 2003).

A compreensão dessas questões é relevante no labor do bibliotecário, tendo em vista que esse profissional, ao desenvolver e aplicar a competência em informação e, portanto, a avaliação, por meio da aprendizagem não formal, assume o papel de educador e auxilia os usuários no uso adequado das TIC, sempre de maneira crítica e reflexiva. Além disso, as competências aplicadas norteariam a variável tarefa, tangenciando a metacognição do processo de aprendizagem deste profissional. Isso porque a referida variável lida com a natureza informacional com a qual o sujeito é confrontado e, com o emprego efetivo das competências e, por conseguinte, da avaliação informacional, será conduzido ao exitoso acesso e uso de informações. 


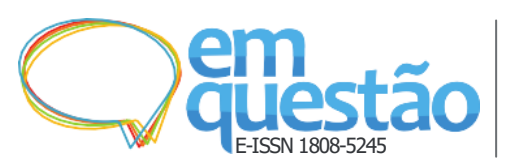

\title{
2.1 Os critérios para avaliação informacional em ambientes colaborativos
}

No tocante à temática de avaliação informacional, habilidade imprescindível ao exercício pleno da competência para lidar com a informação, torna-se inevitável adentrar na discussão dos ambientes colaborativos, na exata medida em que eles estão ditando a maneira como a sociedade lida com a sobrecarga informacional. Nessa dimensão, Minhoto e Meirinhos (2011) sugerem que:

\begin{abstract}
Os serviços de redes sociais constituem, hoje, a plataforma de suporte para o desenvolvimento de comunidades de aprendizagem em contextos institucionais e de comunidades de prática em contextos profissionais. A sua utilização pedagógica como apoio ao ensino presencial pode ser vantajosa pois apresentam uma multiplicidade de ferramentas de comunicação e trabalho, que antes eram e xclusivas das plataformas de e-learning. Pelas suas características comunicativas e interativas, estabelecem as condições de suporte para a dinâmica necessária à colaboração: a socialização. (MINHOTO; MEIRINHOS, 2011, p. 26, grifo nosso).
\end{abstract}

Esses e outros ambientes colaborativos apresentam vantagens aos sujeitos, articulando o processo de interação comunicativa e aumentando as competências sociais. Assim, possibilitam que essas pessoas desenvolvam o seu senso crítico e participem socialmente, acessando informações, assimilando-as e, por consequência, construindo novos conhecimentos. Com isto, desdobra-se um constante círculo de aprendizagem.

Espaços desta natureza são explorados pelos bibliotecários em seu cotidiano. Nesses espaços, os bibliotecários naturalmente recuperam informações nas redes sociais e na internet como um todo, para algum quefazer laboral. Isso se deve à fusão que tais redes fazem de vida pessoal com vida profissional, haja vista que sempre compartilham algo no Facebook, Instagram e/ou Twitter que remete a questões laborais, e o cidadão profissional vê naquele material potencialidades aproveitáveis em seu trabalho.

Nessa perspectiva, o fator avaliação crítica é essencial, especialmente na atual conjuntura de disseminação de desinformação. Nessa conjuntura, o neologismo pós-verdade ganha destaque, pois representa o contexto em que emoções e crenças pessoais influenciam sobremaneira a formação da opinião pública. Schwab (2016) faz uma reflexão interessante ao falar do cidadão nos ambientes colaborativos de informação, descrevendo duas tendências: 


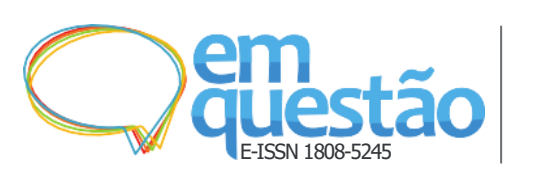

[...] o empoderamento e o desempoderamento. Os indivíduos sentem-se empoderados por mudanças tecnológicas que facilitam a coleta de informações, a comunicação e a organização e, além disso, estão experimentando novas maneiras de participar da vida cívic a. [...] e desempoderados, em termos de sua capacidade de influenciar e de ser ouvidos pelas instituições dominantes e pelas fontes de poder dos governos. (SCHWAB, 2016, p. 59, grifo nosso).

O autor acrescenta que "ferramentas da quarta revolução permitem novas formas de vigilância e outros meios de controle" social, por vezes, um tanto contraditórios à sociedade democrática em que se vive. Destaca-se, justamente, o quanto a disseminação de informações nesses ambientes informacionais web tem contribuído para a proliferação de desinformações, especialmente em situações de corrida eleitoral.

Em função das razões apresentadas pelo autor, faz-se necessário estabelecer critérios de avaliação informacional, entendendo, maiormente, que o indivíduo compreende a informação quando a assimila, lhe atribui significado e a apreende. Barreto (2009) acrescenta que nesse processo é mister considerar:

a) o contexto do texto, enquanto uma estrutura de informação;

b) a atitude do indivíduo em relação ao tempo e ao espaço de interação;

c) o estoque de informação acumulado na memória do indivíduo;

d) as suas possibilidades de apreensão simbólica da informação.

Niqresh (2019) faz uma revisão bibliográfica das perspectivas da avaliação da informação, trazendo à luz o fato de que a maioria dos estudos falam do aspecto da fonte informacional em detrimento do conteúdo propriamente dito. Nesta investigação, preocupa-se também com a avaliação do conteúdo e considera essa ação imprescindível para que seja viável o julgamento da adequação da informação à demanda a que responderá. O que coaduna com a perspectiva Arouck (2011), adaptada na figura 1. 


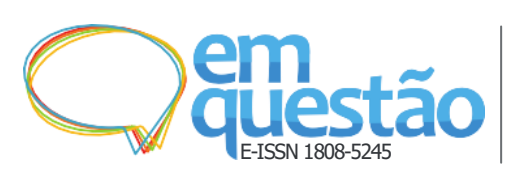

Figura 1 - Critérios de avaliação da informação

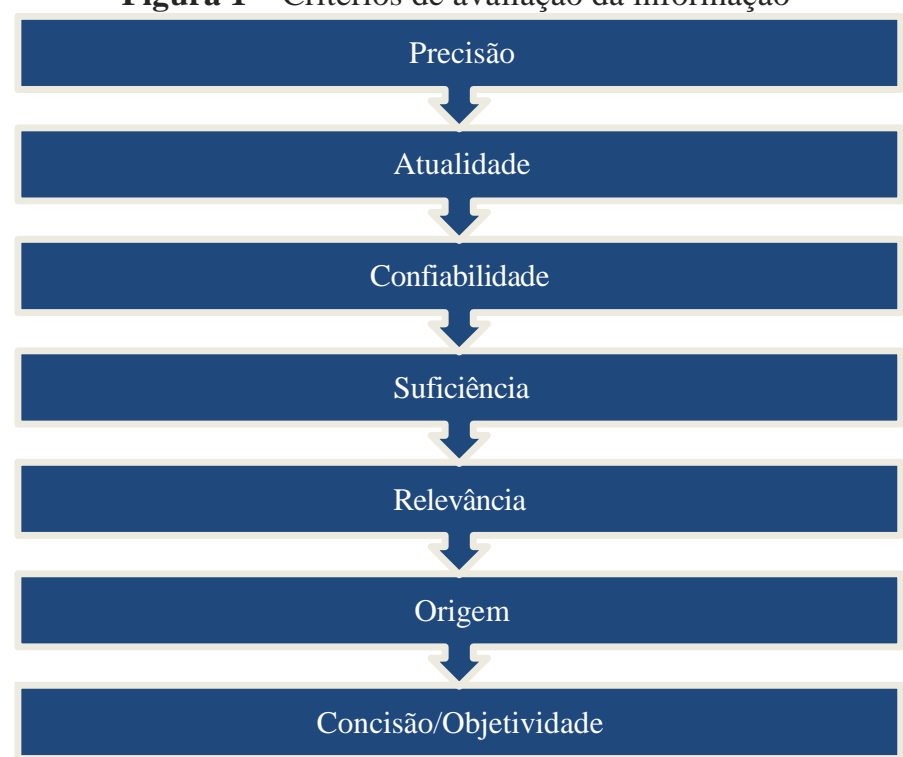

Fonte: Elaborado pelas autoras, adaptado de Arouck (2011).

Portanto, é preciso atentar à precisão, pois a informação precisa ser livre de erros; à atualização, que identifica quão recente é o conteúdo da informação obtida; à confiabilidade - identifica se a fonte e o conteúdo da informação têm credibilidade perante o público-alvo; à suficiência, que consiste na satisfatoriedade da informação fornecida para o fim a que se propõe; à relevância- identifica o valor, o interesse ou a implicação da informação; à origem/autoria - localiza o ente representado pelo registro da informação quando necessário e, por fim, atentar à concisão/objetividade da informação, pelas quais alguém apresenta um conteúdo de modo reduzido, atendo-se ao essencial (AROUCK, 2011). É inevitável constatar que os critérios elencados aqui são imprescindíveis e devem ser considerados no contexto do fazer bibliotecário, especialmente na ocasião da elaboração de um script de avaliação em seu cotidiano pessoal e laboral.

\section{0 percurso metodológico}

$\mathrm{Na}$ intenção de alcançar o objetivo desta investigação, foi delineado o percurso metodológico. Desse modo, a pesquisa quanto ao nível enquadra-se em descritiva. Hymann (1967) explica que, nesse caso, menciona-se o caráter descritivo da pesquisa e se registra a maneira pela qual ela ocorre. Este projeto busca conhecer o comportamento de um determinado grupo de indivíduos, os 


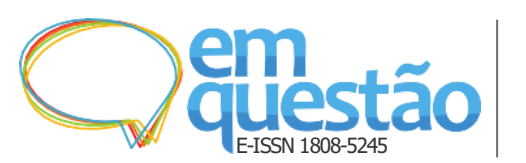

bibliotecários, por isso pode-se inferir que se trata de um levantamento ou survey. A abordagem adotada é a qualitativa e quantitativa, já que embora exista a tendência de mensuração dos dados, não se exclui a possibilidade de tratá- los qualitativamente. Inicialmente foi feito um levantamento bibliográfico a partir de portais, repositórios e bases de dados, o que permitiu compreender aspectos sobre a avaliação da informação e a relação dos bibliotecários com o uso das TIC.

Buscou-se investigar os bibliotecários ativos no mercado de trabalho, para que os dados refletissem a realidade de sua atuação. Para contatá- los, foi necessária a colaboração do Conselho Regional de Biblioteconomia da quinta região, que forneceu dados relativos ao quantitativo de profissionais com cadastros ativos e quites com a anuidade. Até 20 de março de 2019, o banco de dados do CRB5 contabilizou 595 bibliotecários ativos na Bahia que se enquadram nas especificações supracitadas, e que, portanto, estavam aptos a participar do estudo.

Elaborou-se um questionário no Google Formulários com base nos preceitos da American Library Association (ALA) e Santos (2015). As questões apresentavam situações em que fosse possível perceber a atitude dos profissionais em relação ao uso das TIC e à avaliação informacional em ambientes colaborativos. Desse modo, tornou-se viável realizar o propósito da pesquisa. $\mathrm{O}$ instrumento de coleta de dados foi enviado aos bibliotecários no mês de abril de 2019 e 116 profissionais responderam. Para a análise dos dados coletados, foi preciso criar duas categorias temáticas, identificadas como Categoria 1 - Caracterização dos respondentes e Categoria 2 - Avaliação informacional e uso de recursos tecnológicos. Pontua-se que os respondentes foram identificados como Bibliotecários1-116; eles são designados no texto da seguinte forma: (B1-B116).

\section{Apresentação dos dados e discussão dos resultados}

A categoria 1 preocupou-se em caracterizar os respondentes para delineamento do seu perfil. Os dados revelaram (Gráfico 1) que na profissão ainda predomina o gênero feminino, conforme observado por Santos (2015), Santos e Barreira 


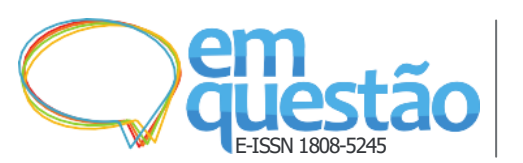

(2014, 2017, 2019). Pires (2016) acrescenta que com o passar dos anos, foi observado que os cursos de graduação em Biblioteconomia se consolidaram como majoritariamente femininos, tanto na atuação profissional quanto nas universidades.

A predominância do gênero feminino na área demonstra que, por meio da competência em informação, as mulheres podem adquirir o conhecimento sobre a própria capacidade cognitiva, participando mais criticamente dos espaços informacionais. Isso se torna cristalino no contexto atual, no qual muito se discute sobre empoderamento feminino e sobre o lugar da mulher na sociedade enquanto pessoa e profissional. Segundo Silva (2015), dados internacionais apontam que existe uma diferença de gênero no uso das TIC: as meninas tendem a utilizar o computador com a finalidade de realizar trabalhos escolares enquanto os meninos o fazem com objetivo mais lúdico, sendo para elas, portanto, um contato mais engessado.

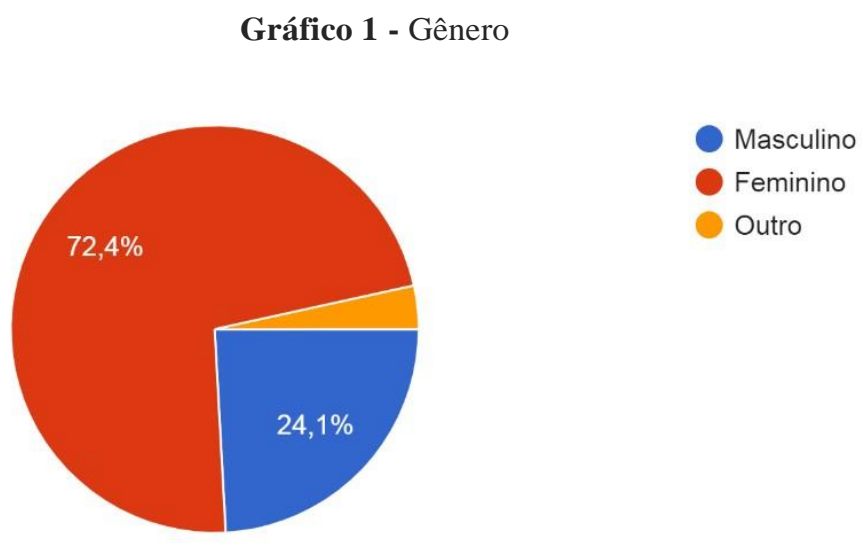

Fonte: Dados da pesquisa.

Ampliando o escopo do perfil, a pesquisa identificou que a faixa etária dos respondentes está acima dos 36 anos (70\%), conforme demonstra o Gráfico 2. Infere-se, logo, que os respondentes estão inseridos em um contexto informacional mais favorável ao uso de TIC em seu cotidiano. Pereira e Polivanov (2012) reforçam essa posição ao dizer que a convivência dos jovens com o conjunto tecnológico faz com que a tecnologia esteja articulada com o seu modo de vida. Certamente essa realidade se distingue da de gerações passadas, que não tinham essa mesma relação de afinidade com o uso de 


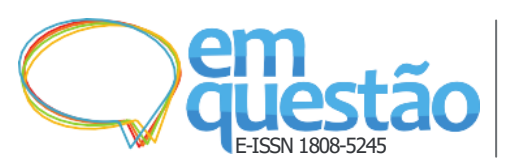

equipamentos eletrônicos. Assim, quanto mais jovem, maior essa afinidade; em contrapartida, quanto mais velho, mais inibida essa afinidade se mostraria.

Gráfico 2 - Faixa etária

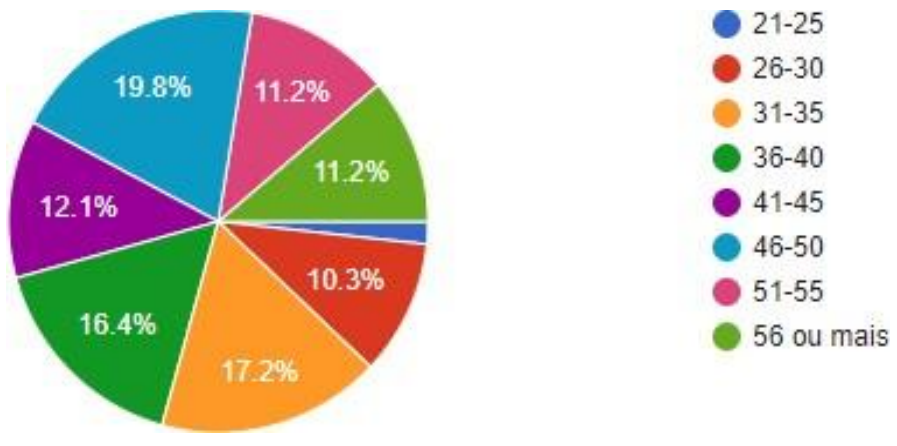

Fonte: Dados da pesquisa.

O uso competente das TIC é compromisso incontornável dos profissionais do século XXI, então, no seu processo formativo é salutar que esse tema componha o escopo de aprendizagem. No caso dos bibliotecários, Brito e Vasconcelos (2017) apontam que a partir de 2001, com as novas diretrizes curriculares implantadas para a Biblioteconomia do Brasil do século XXI, o parecer 492 mostrou uma preocupação com a formação deste profissional no que tange ao desenvolvimento e utilização de novas tecnologias. Estas deveriam atender às demandas sociais de informação produzidas pelas transformações tecnológicas que caracterizam o mundo contemporâneo.

Por esse motivo, a pesquisa buscou conhecer o período que contempla o ano de formação dos respondentes, já que os que se graduaram após as supracitadas mudanças certamente têm maior familiaridade com o uso das TIC. O Gráfico 3 revela que mais de $50 \%$ dos respondentes se formaram no período de 2006 e 2016. Assim, os partícipes desta investigação tiveram acesso a disciplinas que possivelmente ajudaram na compreensão das TIC em seu cotidiano laboral. 


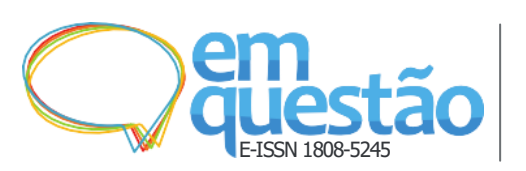

Gráfico 3 - Período de conclusão de curso

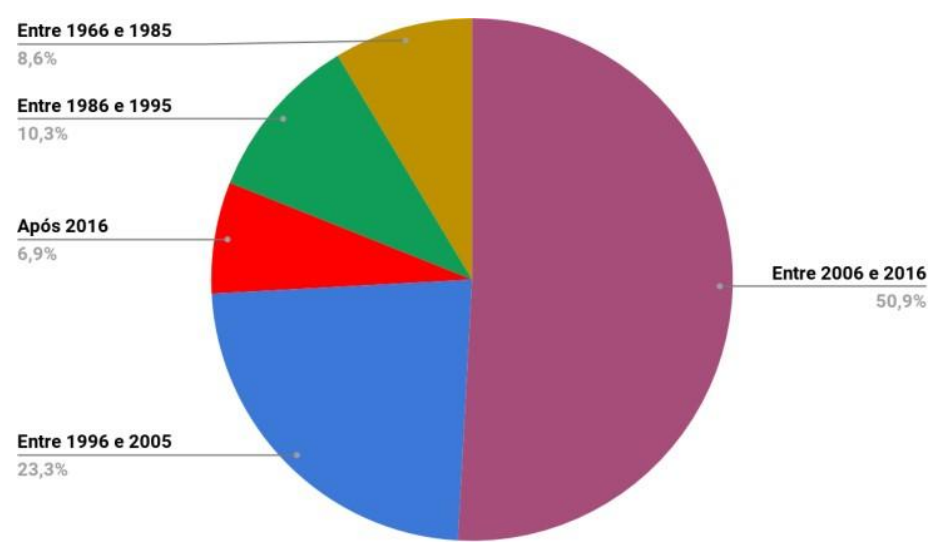

Fonte: Dados da pesquisa.

Indagou-se dos sujeitos da investigação o período em que ingressaram no CRB5, condição sine qua non para o exercício profissional, pois assim se pode identificar o início de suas atividades laborais. O Gráfico 4 ilustra que a maioria dos respondentes efetuaram o cadastro entre 2001 e 2016. Fazendo uma comparação entre os Gráficos 3 e 4, infere-se que a atuação na área ocorre imediatamente após a conclusão do curso, o que demonstra o quanto a Biblioteconomia é um campo promissor, como foi vislumbrado em estudos anteriores (SANTOS, 2015; SANTOS; BARREIRA, 2017).

Gráfico 4 - Período de inscrição no Conselho Regional de Biblioteconomia da $5^{\circ}$ Região

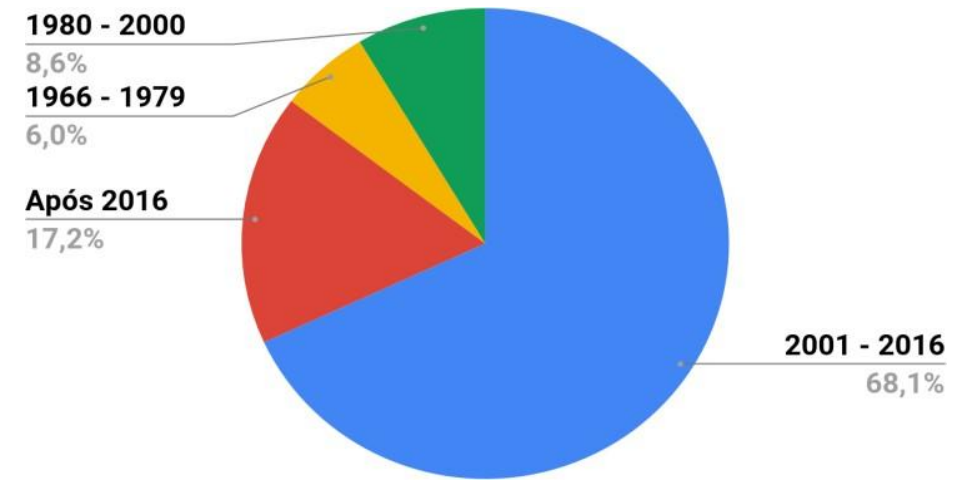

Fonte: Dados da pesquisa.

O contexto de atuação laboral dos bibliotecários é diverso e composto de diferentes unidades de informação no âmbito público e privado. Os dados do Gráfico 5 demonstram que é significativo o percentual daqueles que desenvolvem as suas atividades em bibliotecas universitárias públicas $(26,7 \%)$ e privadas $(16,4 \%)$, ambientes que, por suas características, denotam a 


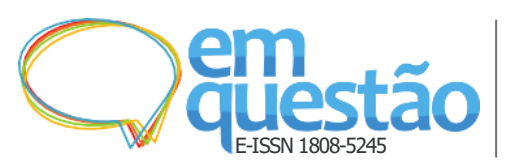

necessidade premente de avaliar as informações, quer as que provêm de fontes tradicionais, quer as que demandam uso das TIC.

Gráfico 5 - Tipo de unidade informacional em que atuam

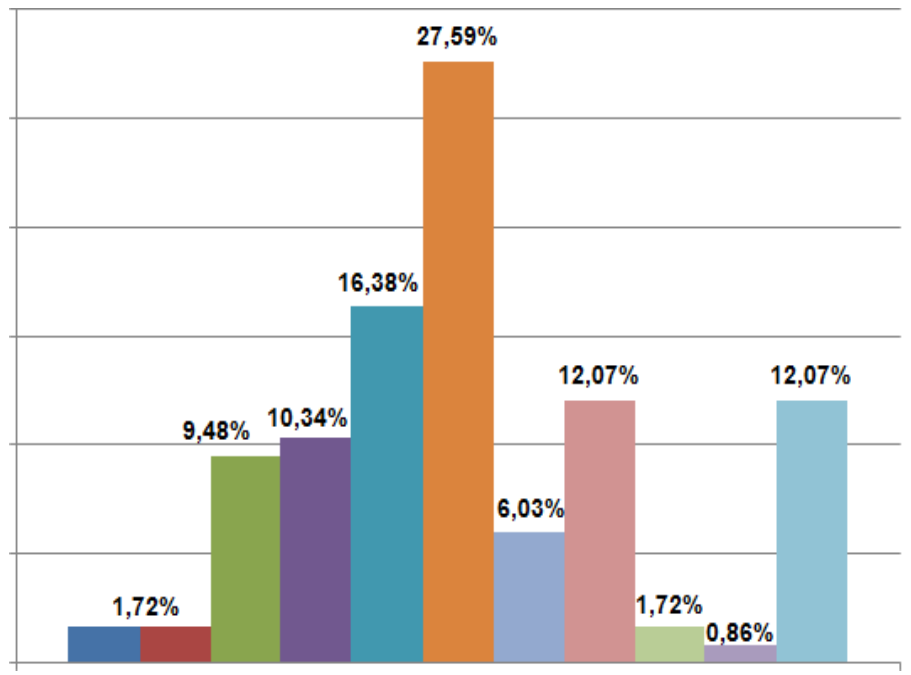

- Arquivo Privado

- Arquivo Público

- Biblioteca de Escola Particular

- Biblioteca de Escola Pública

- Biblioteca de Universidade Privada

= Biblioteca de Universidade Pública

- Biblioteca Especializada (Órgãos Federais e

afins)

- Biblioteca Pública

- Docente de Universidade Pública

- Museu Privado

= Outros

Fonte: Dados da pesquisa

A Categoria 2 apresenta dados, instigantes a esta investigação, que elucidam como os bibliotecários usam os recursos tecnológicos e como procedem à avaliação das informações. Para tanto, inquiriu-se inicialmente acerca do contato que os respondentes têm com as TIC no seu corriqueiro ambiente de trabalho. Os dados demonstram que $76,7 \%$ dos respondentes usam tais recursos de forma contínua, o que revela a familiaridade que esses profissionais mantêm com as TIC.

Gráfico 6 - Uso de tecnologias da informação e comunicação no ambiente de trabalho

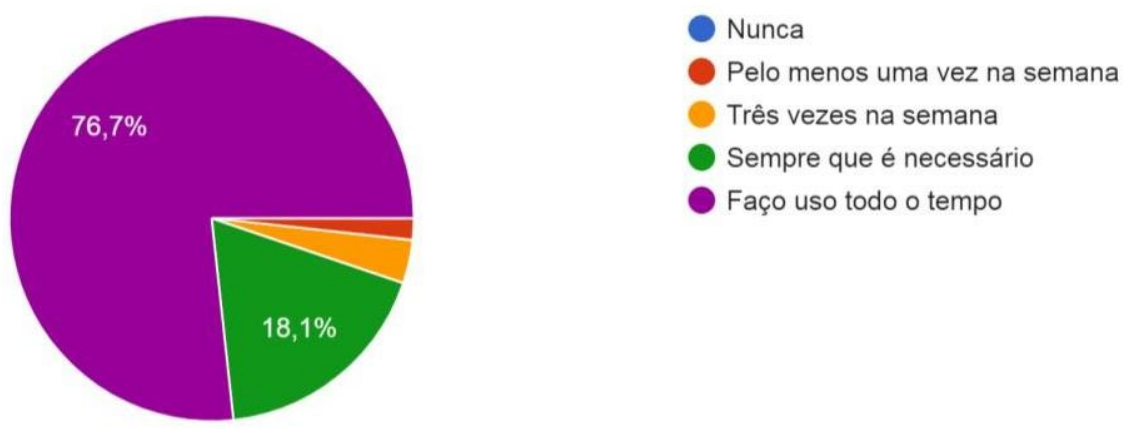

Fonte: Dados da pesquisa.

Outrossim, a pesquisa buscou perceber o uso, pelos bibliotecários, de recursos apropriados para atender eficazmente as demandas e para fidelizar o 


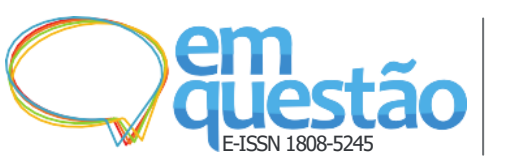

usuário, convencendo-o a usar os serviços da unidade na qual esses bibliotecários laboram. Admite-se que esses profissionais selecionam e avaliam recursos imprescindíveis que colaboram para uma resposta assertiva aos usuários. Dentre esses recursos, ganham destaque os buscadores online, que $46 \%$ dos respondentes declararam usar o tempo todo e que $39 \%$, por outro lado, sinalizaram usar em situações em que sentem necessidade. Esse dado é bastante pertinente, tendo em vista que, com o avanço das TIC, cada vez mais se torna inevitável o uso da internet para pesquisas diversas, conforme ratificam Lemos e Lévy (2010). Em relação às bibliotecas virtuais, mais de 50\% responderam que faziam uso delas apenas quando necessário. Já quando se trata de repositórios, bancos ou bases de dados, $50 \%$ dos respondentes disseram fazer uso sempre que necessário.

No que diz respeito a tag e subscrição, há uma grande incidência de respostas que apontam para a não utilização, algo curioso, tendo em vista que, nas redes sociais da web, o tempo todo se usam as tags para recuperar informações. A subscrição, por sua vez, é muito presente no cotidiano dos sujeitos, pois a todo momento cadastram-se e- mails em sites, que enviam notícias de acordo com o perfil do cadastro. Quando a questão coloca em xeque as redes sociais, $63 \%$ dos respondentes afirmam que fazem uso o tempo todo ou sempre que julgam necessário.

Gráfico 7 - Uso das ferramentas das tecnologias de informação

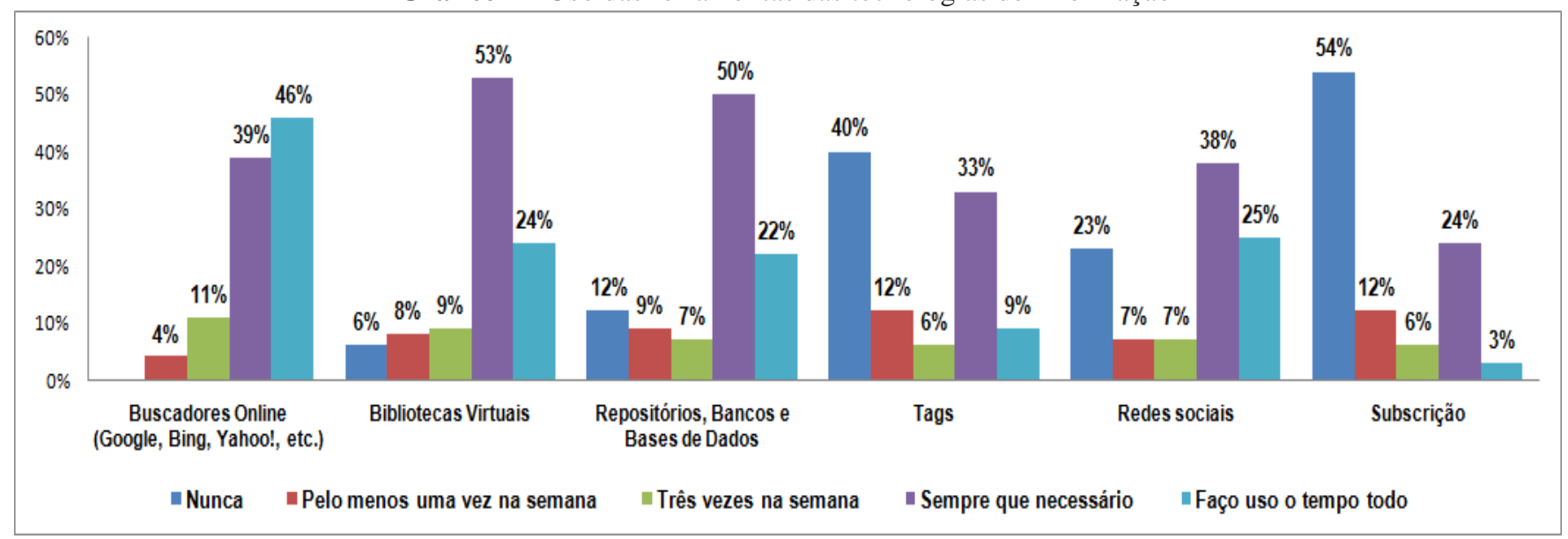

Fonte: Dados da pesquisa. 


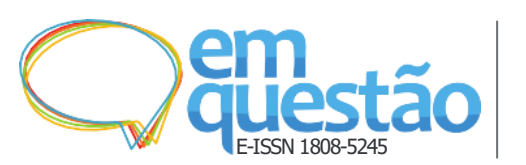

Ainda no contexto das redes sociais, é imperativo recuperar Schwab (2016), que menciona a vigilância como algo necessário nesse meio colaborativo, no sentido de que é preciso ter critérios avaliativos para uso de informações que são compartilhadas de maneira desenfreada na web. Foi possível perceber inicialmente que os que acenaram positivamente para a utilização das redes sociais usam essas redes para a 'divulgação de atividades culturais' (B1) e de 'serviços e produtos da biblioteca na qual atuo (B42), e também as usam 'como instrumento de aproximação e comunicação entre a biblioteca pública e a comunidade’ (B8). Essas percepções vão ao encontro do postulado por Santos e Santos (2014), que recuperam a perspectiva de Castells ao falar da intercomunicação enquanto um fenômeno de comunicação interativo e colaborativo no ciberespaço, presente no modo como as pessoas estão se comunicando nas redes sociais, Twitter e blogs. Esse conceito evidentemente pode ser aplicado na comunicabilidade institucional no âmbito de arquivos públicos, bibliotecas e museus.

Por outro lado, identificou-se o comportamento dos profissionais em relação às suas escolhas informacionais e também como partícipes dessa comunidade interativa, já que estão nesses ambientes com o intuito de 'ler mensagens, notícias, participar de grupos e eventos' (B53). Alguns dos comentários dos profissionais a esse respeito foram: 'consulto blogs, páginas e perfis voltados para a biblioteconomia, tecnologia da informação, aprendizagem de idiomas, desenvolvimento de pesquisas em diversas áreas, entre outros' (B76); 'faço uso para pesquisa, acompanhar informações e novidades na área de biblioteconomia' (B108); '[uso as redes] para postar informações da biblioteca e verificar outras' (B110). Isso demonstra a preocupação dos bibliotecários com a sua participação como produtores e usuários da informação nesses ambientes colaborativos, nos quais está presente a maior parte dos usuários da geração Y e Z, reconhecendo, portanto, as potencialidades das redes. Outrossim, ao pontuar a busca por informações referentes à profissão, revela atenção a aspectos da avaliação informacional, como a precisão, a atualização, a relevância e a autoria do que é recuperado. 


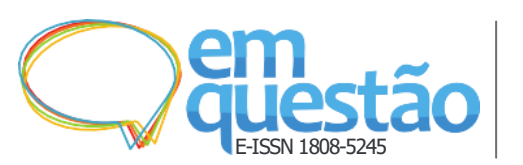

Ao serem questionados como precediam a avaliação da informação recuperada na web, houve incidência da resposta de que priorizam a apuração da fonte da informação - tanto o veículo em que ela foi divulgada como quem produziu o seu conteúdo - e de buscar a mesma informação em mais de uma fonte, para averiguá- la. Ademais, também se respondeu que havia consulta aos colegas, demonstrando que o diálogo e a colaboração figuram nesse processo. É perceptível que essas respostas estão voltadas para uma avaliação mais universalizada, contudo, esse estudo reafirma a importância de considerar uma avaliação crítica e reflexiva das fontes e também do conteúdo, fundamentandose na sua precisão, atualização, confiabilidade, suficiência, relevância, origem e concisão/objetividade. Envolve, logo, a metacognição, na qual há a autoavaliação dos processos cognitivos e, é nesse contexto que se pode verificar a pertinência dessa informação no decurso de aprendizagem dos sujeitos. Salienta-se que somente o respondente B94 menciona a importância de proceder uma avaliação crítica da informação ele ita.

Por isso, foi primordial para esta pesquisa que os bibliotecários pudessem classificar diferentes notícias de veículos de informações quanto ao nível de confiança do conteúdo, especialmente para fins de utilização na sua atividade laboral. O Gráfico 8 faz alusão às respostas referentes a uma notícia do site Sensacionalista que dava conta de uma petição para trocar a Constituição por meme. A maioria dos respondentes $(71 \%)$ afirmou que a notícia não era confiável. Salienta-se que o próprio site já anuncia ser isento de verdade, uma vez que tem a finalidade de produzir e difundir sátiras.

Gráfico 8 - Confiabilidade de informações veiculadas na web

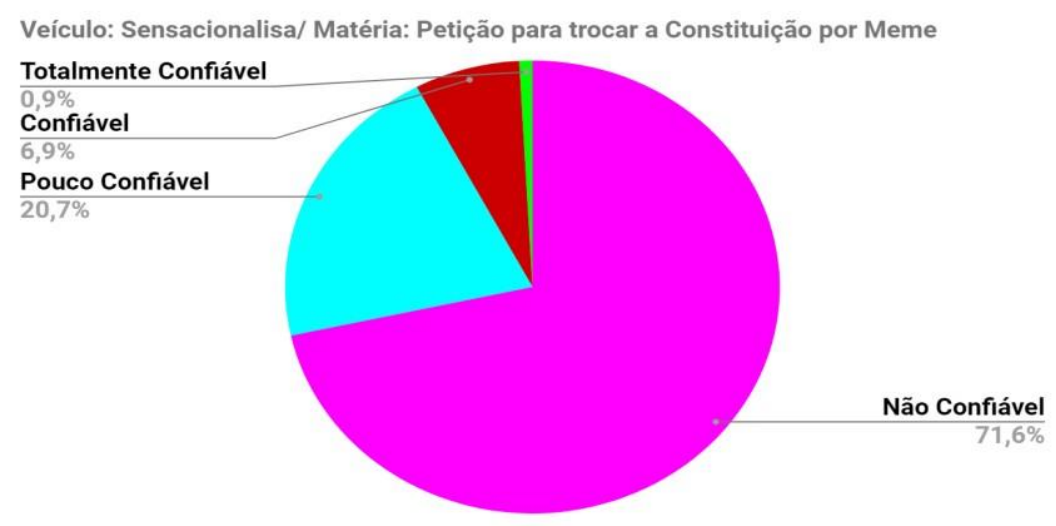

Fonte: Dados da pesquisa. 


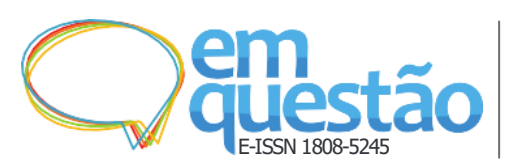

Os bibliotecários, ao responder à questão relacionada à avaliação das informações que buscam na web, afirmaram verificar a confiabilidade contemplando o que Arouck (2011) pontua como critérios para tal. Contudo, ao acessar o link da matéria em questão (Gráfico 8), surpreendentemente oito (8) bibliotecários disseram que era confiável e um (1) disse ser totalmente confiável, algo que gera uma preocupação, já que não se espera que esses profissionais não consigam perceber a real intenção de portais dessa natureza.

Por isso, é importante que o bibliotecário esteja atento às suas próprias competências, pois à medida que o tempo passa, elas precisam ser (re)pensadas e aprimoradas de acordo com as necessidades emergentes da sua práxis (SANTOS; RODRIGUES; SOUZA, 2019). Sabe-se que em um cenário de grandes propagações de desinformações, em que a sátira está inclusa, os sujeitos precisam ter um olhar crítico e reflexivo em relação às informações com que se deparam.

O Gráfico 9 retrata as escolhas dos bibliotecários em relação ao seu grau de confiança a respeito de uma matéria da $\mathrm{BBC}$ que reflete sobre o mito da relação entre autismo e vacina. $80 \%$ dos respondentes a classificaram como confiável ou totalmente confiável. Estima-se que aplicaram os critérios de avaliação da informação, destacando-se aqueles relacionados a precisão e relevância (implicações), já que acenaram para a confiabilidade de uma notícia que usa resultados de pesquisas científicas para embasar a sua argumentação. .

Gráfico 9 - Confiabilidade de informações veiculadas na web

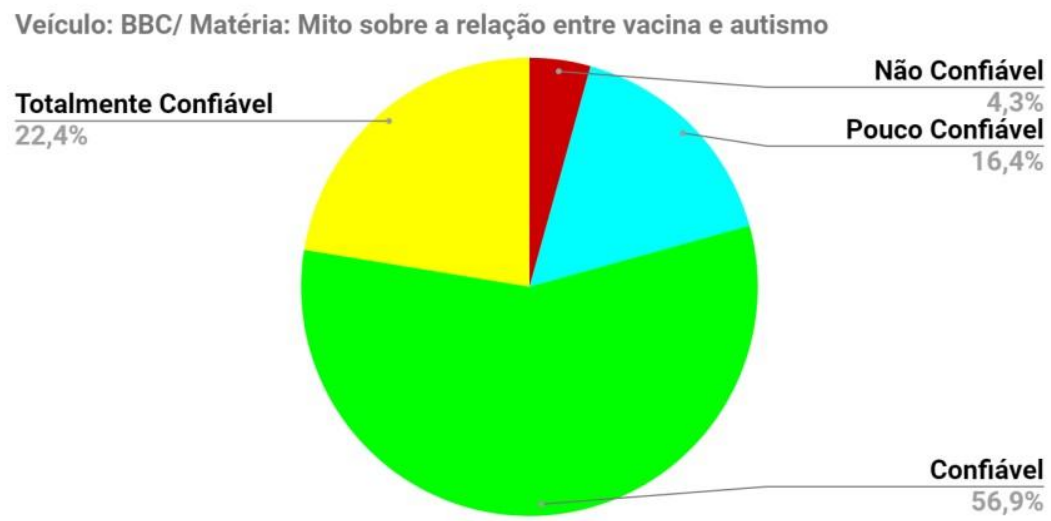

Fonte: Dados da pesquisa. 
Já o Gráfico 10 representa a avaliação da matéria intitulada Cuba já registra a volta de 196 médicos que estavam no Brasil, veiculada no site R7 Notícias. Neste caso, $50 \%$ dos respondentes disseram que a notícia era confiável, mas uma quantidade considerável (37\%) optou por considerá- la não confiável ou pouco confiável. Isso leva a crer que esses respondentes analisaram apenas uma única fonte, que foi aquela disponibilizada por esta investigação, pois a notícia também foi veiculada em outros portais de notícias, dentre eles o site da revista IstoÉ, com o título Retornam a Cuba primeiros 196 médicos que estavam no Brasil (2018). Essa escolha, portanto, contradiz a afirmação, feita antes pelos respondentes, de que pesquisam em mais de uma fonte para atestar a confiabilidade das informações.

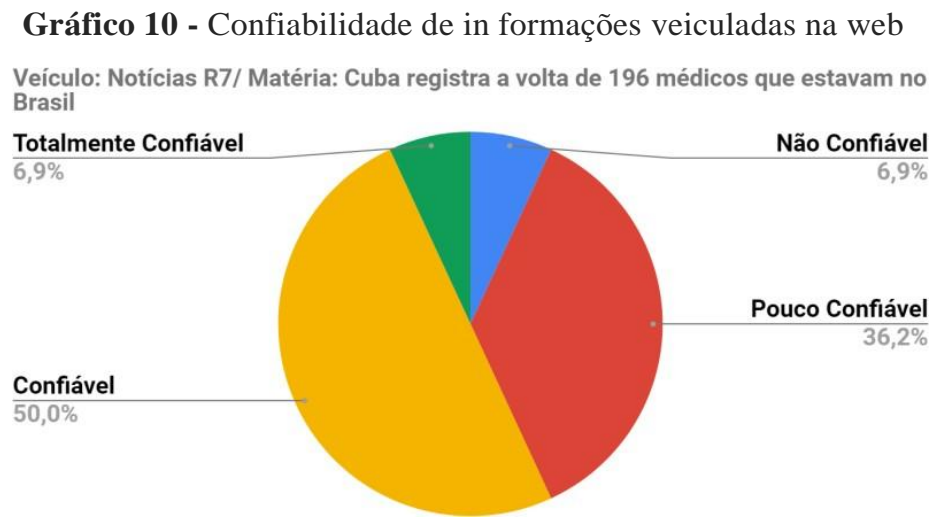

Fonte: Dados da pesquisa.

A matéria Terra plana, publicada por blog homônimo, deu origem aos dados do Gráfico 11. Aqui se observa que $47 \%$ dos respondentes consideraram a matéria como não confiável e $41 \%$, como pouco confiável; não obstante, $12 \%$ (14) dos bibliotecários disseram que a matéria era confiável, o que denota que uma parcela desses profissionais não estão procedendo à avaliação de forma efetiva, tendo em vista que é comprovado cientificamente que a Terra é redonda (BRASIL, 2018). 


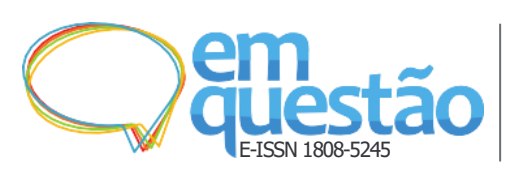

Gráfico 11 - Confiabilidade de in formações veiculadas na web Veículo: Blog Terra Plana/ Matéria: As provas da Terra Plana

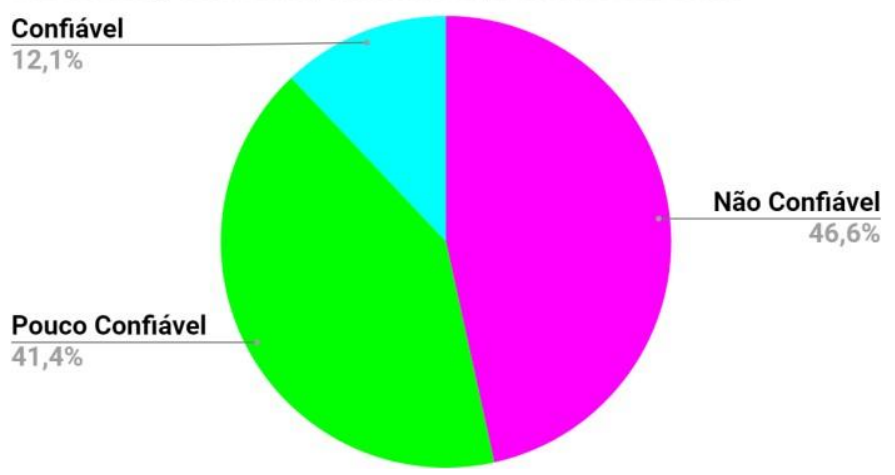

Fonte: Dados da pesquisa.

Gráfico 12 - Confiabilidade de in formações veiculadas na web Veículo: Mundo Educação/ Matéria: A Terra é Plana?

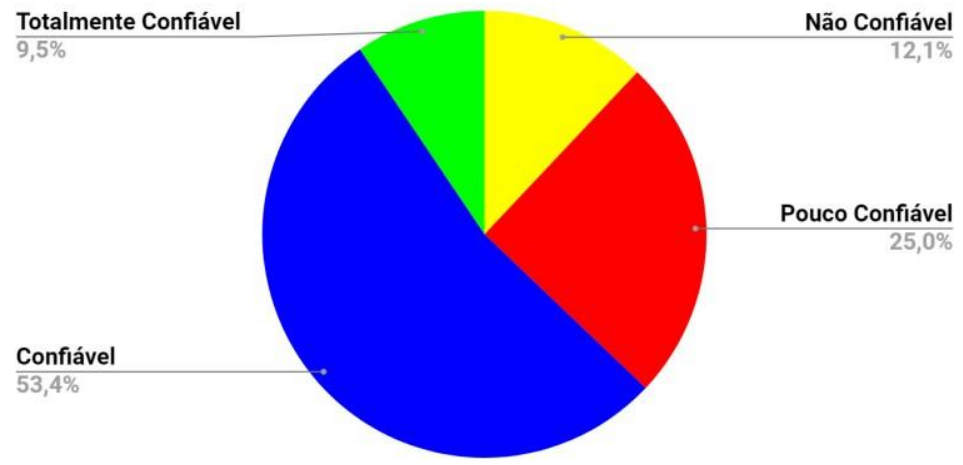

Fonte: Dados da pesquisa.

Em contrapartida, o Gráfico 12 apresenta uma matéria do Mundo Educação, sobre a mesma temática, A Terra é plana?. No título observa-se o caráter interrogativo, estimulando, assim, a criticidade. Em oposição ao noticiário do blog, esta matéria apresenta comprovações científicas de que a Terra é redonda. Nesse caso, 53\% dos bibliotecários disseram ser confiável esse conteúdo informacional; entretanto, $25 \%$ disseram que esse conteúdo era pouco confiável. Esse último percentual pode ter relação com a ideia que muitos profissionais cultivam, de que somente trabalhos técnicos e científicos devem ser dignos de confiança. Ademais, é possível que esteja em consonância com as suas crenças e valores e, por isso, inclinam-se a considerar duvidosa uma informação verdadeira ou vice e versa.

Percebe-se, portanto, que os bibliotecários aplicam, em maiores ou menos proporções, os critérios de avaliação da informação, quais sejam: precisão, atualização, confiabilidade, suficiê ncia, relevância, origem e 


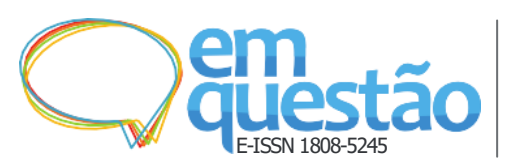

concisão/objetividade. Há uma tendência ao direcionamento do foco avaliativo para a fonte informacional e isso foi também apontado por Niqresh (2019). Contudo, ao avaliar as notícias efetivamente (gráficos 8-12), ficou claro que esses profissionais precisam fazê- lo de maneira crítica e reflexiva, para que possam identificar as informações úteis, tanto para a sua vida pessoal quanto laboral, distinguindo-as das desinformações.

Ademais, admite-se que para a avaliação no ambiente colaborativo web, é importante considerar o nome da página, para a distinção de informação pessoal, profissional e institucional; o domínio da página; a declaração de autoria do site; as fontes mencionadas (o ideal é fazer a triangulação desses dados, checando-os); o estilo de redação, pois os documentos em que se usam hipérboles tendem a ser de procedência duvidosa; a estética, haja vista que as páginas questionáveis podem apresentar um design inapropriado, e a análise das mídias sociais, cuja finalidade é checar se as informações veiculadas correspondem às mesmas informações em todas as plataformas.

\section{Considerações finais}

A avaliação informacional em ambientes colaborativos parece ser uma realidade emergente. Quando se trata dos bibliotecários ativos no mercado de trabalho, isso se torna mais evidente, dado que quando se trabalha a competência em informação desses profissionais nos projetos de pesquisa, questões dessa natureza assinalam investigações profícuas.

Nesse sentido, para alcançar o fim deste estudo, foi preciso inicialmente caracterizar os participantes, com a finalidade de conhecer suas características e, assim, melhor discutir os demais resultados. Permanece a tendência dos últimos estudos, que demonstram que embora tenha crescido o número de bibliotecários do gênero masculino, há a predominância ainda do feminino. A maioria dos bibliotecários estão na faixa etária acima dos 36 anos de idade e estão ativos no cadastro do CRB5 desde 2006. Metade dos respondentes formaram-se na última década, então em sua formação certamente tiveram contato com as TIC, já que a partir de 2001, os cursos passaram a adequar-se a essa demanda. Ademais, as bibliotecas universitárias de instituições públicas e privadas se destacam como 


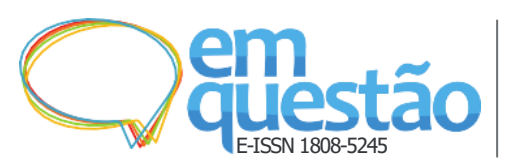

os ambientes de trabalho que mais absorvem mão de obra. Talvez esse dado se justifique pelo fato de que há uma regulamentação Ministério da Educação (MEC) que exige a presença do bibliotecário em bibliotecas universitárias.

Obtiveram-se também dados instigantes a esta investigação, que dão conta do uso de recursos tecnológicos e da avaliação das informações feitas pelos bibliotecários investigados. A grande maioria dos profissionais usam os recursos das TIC o tempo todo em suas atividades laborais. Continua um cenário favorável ao uso dos buscadores e das redes sociais, mas há uma sinalização desfavorável para tags e subscrição, algo que parece um tanto curioso, já que nesses ambientes colaborativos as tags servem para recuperar discussões e o tempo todo se insere o e- mail em sites para receber informações de interesse.

Há uma tendência para o uso desse ambiente colaborativo para disseminar ações culturais, além disso, o bibliotecário assume seu papel como produtor e usuário da informação. Os critérios usados para avaliação da informação contemplam aqueles encontrados na literatura como assertivos, contudo, ao avaliar notícias, na prática, foi possível perceber fragilidades consideradas preocupantes, pois alguns profissionais não conseguem distinguir as informações de desinformações. Neste ponto, sobretudo, esta investigação desponta como agregadora, visto que ao trazer à luz questões dessa natureza, ela chama o bibliotecário para a práxis consciente, para a autocrítica de seu fazer e para a busca de aperfeiçoamento profissional constante para que, assim, ele evite as armadilhas deste mundo altamente conectado.

\section{Referências}

AMARO, Bianca. O bibliotecário e o seu relacionamento coma tecnologia. In: RIBEIRO, Ana Carolina Mendonça Lemos; FERREIRA, Pedro Cavalcanti Gonçalves (org.). Bibliotecário do Século XXI: pensando o seu papel na contemporaneidade. Brasília: Ipea, 2018. p. 33-45.

AROUCK, Osmar. Atributos de qualidade da informação. 2011. Dissertação (Mestrado em Ciência da Informação) - Faculdade de Ciência da Informação, Universidade de Brasília, Brasília, 2011.

BARRETO, Aldo. Mediações digitais. DataGramaZe ro, [s. l.], v. 10, n. 4, p. 118, 2009. 
BELLUZO, Regina Célia Baptista. Competência em informação no Brasil: cenários e espectros. São Paulo: ABECIN, 2018.

BRASIL, Marco Moriconi. A Terra é redonda. Ciência hoje, Rio de Janeiro, 26 dez. 2018

BRITO, Rosa Zuleide Lima de; VASCONCELOS, Josivan Coêlho dos Santos. Analise preliminar dos currículos dos cursos de Biblioteconomia da região nordeste acerca da formação tecnológica dos seus egressos. In: CONGRESSO BRASILEIRO DE BIBLIOTECONOMIA, DOCUMENTAÇÃO E CIÊNCIA DA INFORMAÇÃO, 27., 2017, Fortaleza. Anais [...]. Fortaleza: FEBAB, 2017. p. 1-6.

CARNEIRO, Bárbara Luíza Ferreira et al. Aprendizagem móvel, competência em informação e mediação: interlocução sob a ótica do paradigma social da Ciência da Informação. Revista eletrônica de biblioteconomia e ciência da informação, Santa Catarina, v. 23, n. 52, p. 34-47, 2018.

COMISSÃO DAS COMUNIDADES EUROPEIAS. Memorando sobre aprendizagem ao longo da vida. Bruxelas: COMISSÃO DAS COMUNIDADES EUROPEIAS, 2000.

FREIRE, Paulo. Pedagogia do oprimido. São Paulo: Paz e Terra, 1987.

HATSCHBACH, Maia Helena de Lima; OLINTO, Gilda. Competência em informação: caminhos percorridos e novas trilhas. Revista Brasileira de Biblioteconomia e Documentação, São Paulo, v. 4, n. 1, p. 20-34, 2008.

HYMANN, Hebert. Planejamento e análise da pesquisa: princípios, casos e processos. Rio de Janeiro: Lidador, 1967.

LEMOS, André; LÉVY, Pierre. O futuro da internet: em direção a uma ciberdemocracia. São Paulo: Paulus, 2010.

MINHOTO, Paula; MEIRINHOS, Manuel. As redes sociais na promoção da aprendizagem colaborativa: um estudo no ensino secundário. Educação, Formação \& Tecnologias, [s. l.], v. 4, n. 2, p. 25-34, 2011.

NIQRESH, Mohamed. Mechanisms for the appraisal of electronic information resources. International Education Studies, Ontario, v. 12, n. 2, p. 67-81, 2019.

PEREIRA, Vinicius Andrade; POLIVANOV, Beatriz. Entretenimento como linguagem e materialidades dos meios nas relações de jovens e tecnologias contemporâneas. In: BARBOSA, Lívia (org.). Juventudes e gerações no Brasil contemporâneo. Porto Alegre: Sulina, 2012. 
PIRES, Hugo Avelar Cardoso. Relações de gênero e a profissão bibliotecária na contemporaneidade: panorama nacional e os motivos da entrada masculina em curso majoritariamente feminino. 2016. Dissertação (Mestrado em Ciência da Informação) - Programa de Pós-graduação em Ciência da Informação, Universidade Federal de Minas Gerais, Belo Horizonte, 2016.

QUEIROZ, Malthus Oliveira. Dicionário sucesso da língua portuguesa. Recife: Sucesso, 2014.

RETORNAM a cuba primeiros 196 médicos que estavam no brasil. Isto é, São Paulo, 16 nov. 2018.

RIBEIRO, Célia. Metacognição: um apoio ao processo de aprendizagem. Psicologia, Porto Alegre, v. 16, n. 1, p. 109-116, 2003.

RUOKOLAINEN, Hilda; WIDÉN, Gunilla. Conceptualising misinformation in the context of asylum seekers. Information Processing \& Management, v. 57, n. 3, p. 102127, 2020.

SANTOS, Jaires Oliveira. Competência em informação dos egressos do curso de Biblioteconomia: uma análise na região Nordeste do Brasil. 142 f. Dissertação (Mestrado em Ciência da Informação) - Universidade Federal da Bahia, Instituto de Ciência da Informação, Salvador, 2015.

SANTOS, Jaires Oliveira; RODRIGUES, Kátia de Oliveira; SOUZA, Larissa de Lima. Atuação do bibliotecário frente as fake news In: Encontro Nacional de Ensino e Pesquisa em Informação, 14., 2019, Salvador. Salvador: Anais..., 2019.

SANTOS, Jaires Oliveira; BARREIRA, Maria Isabel de Jesus Sousa. O bibliotecário do Nordeste Brasileiro: elucubrações do processo de aprendizagem e da competência em informação. Revista Brasileira de Biblioteconomia e Documentação, São Paulo, v. 15, n. 2, p. 237-250, 2019.

SANTOS, Jaires Oliveira; BARREIRA, Maria Isabel de Jesus Sousa. Os bibliotecários baianos: compreendendo a evolução de uma profissão. InCID, Ribeirão Preto, v. 8, n. 1, p. 68-80, 2017.

SANTOS, Jaires Oliveira; BARREIRA, Maria Isabel de J. S. Perfil do bibliotecário baiano: um olhar sobre as décadas de 1980 a 2012. Páginas a\&b, Porto, v. 3, n. 1, p. 146-162, 2014.

SANTOS, Jaires Oliveira; SANTOS, Jackson Guterres. Intercomunicação: mecanismo de aproximação entre os espaços culturais e o público. Biblioo, Rio de Janeiro, v. 4, n. 7, p. 22-22, 2014. 


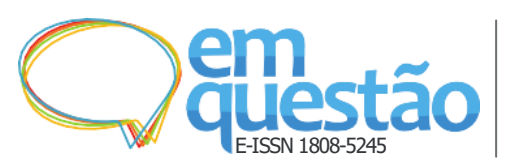

SARACEVIC, Tefko. Ciência da Informação: origem, evolução e relações. Perspectiva em Ciência da Informação, Belo Horizonte, v. 1, n. 1, p. 41-62, 1996.

SCHWAB, Klaus. A quarta revolução industrial. São Paulo: Edipro, 2016.

SILVA, Aline Gonçalves da. Diferenças de gênero no uso das tecnologias da informação e da comunicação: um estudo na biblioteca parque de Manguinhos. In: ENCONTRO NACIONAL DE PESQUISA EM CIÊNCIA DA INFORMAÇÃO, 16., 2015, João Pessoa. Anais [...]. João Pessoa: Fundação Oswaldo Cruz, 2015. p. 1-17.

VALENZUELA, Sebastián et al. The Paradox of Participation versus Misinformation: social media, political engagement, and the spread of misinformation. Digital Journalism, Londres, v. 7, n. 6, p. 802-823, 2019.

\title{
Information evaluation in collaborative environments
}

\begin{abstract}
This study aims to analyze how economically active librarians evaluate information in collaborative environments. We adopted a descriptive approach involving both quantitative and qualitative elements. The target population consisted of librarians active until March 2019 on the professional register of the Conselho Regional de Biblioteconomia da quinta região (CRB5, the regional library association of the Brazilian Northeastern states of Bahia and Sergipe), a population which then amounted to 595 librarians. However, only the 116 librarians who responded to the survey could be included in the final sample. The results were favorable regarding information evaluation in librarians' work, but we did remark some concerning weaknesses, as some respondents had trouble distinguishing information from misinformation.
\end{abstract}

Keywords: Information evaluation. Information and Communication Technologies. Collaborative environments. Information Literacy. Misinformation.

Recebido: $31 / 05 / 2019$

Aceito: 28/01/2020

\section{Como citar}

SANTOS, Jaires Oliveira; BARREIRA, Maria Isabel de Jesus Sousa; SOUZA, Larissa de Lima; GOMEZ, Michelle Pacheco. Avaliação informacional em ambientes colaborativos. Em Questão, Porto Alegre, v. 26, n. 3, p. 327-353, set./dez. 2020. DOI: https://doi.org/10.19132/1808-5245263.327-353. 
${ }^{1}$ Este artigo apresenta resultados do projeto de pesquisa contemplado com bolsas de Iniciação Científica (Programa Permanecer - edital 2018/ 2019), da Universidade Federal da Bahia, sob a coordenação e orientação da professora Jaires Oliveira, pesquisadora do grupo de pesquisa Comporti. 